\title{
The Mechanisms of Particle Kinetics and Dynamics Leading to Seismic Emission and Sunquakes
}

\author{
V.V. Zharkova
}

Published online: 26 September 2008

(C) Springer Science+Business Media B.V. 2008

Erratum to: Solar Phys (2008) 251: 641-663

DOI 10.1007/s11207-008-9216-6

Please note the following changes in the text:

On page 643, the reference to Moradi et al. (2006) should be changed to Moradi et al. (2007).

On page 643, twice on page 644 (Section 2.1.3), twice on page 658, and on page 661, the reference to Besliu-Ionescu et al. (2006) should be changed to Besliu-Ionescu et al. (2005).

On page 644, Section 2.1.2, the reference to Besliu-Ionescu et al. (2006) should be changed to Martínez-Oliveros, Moradi, and Donea (2008).

On page 644, Section 2.1.3, the title should be Flare of 6 April 2001.

On page 645, Section 2.1.5, the reference to Besliu-Ionescu et al. (2006) should be removed.

On page 654, the reference to Besliu-Ionescu et al. (2006) should be changed to MartínezOliveros, Moradi, and Donea (2008).

Pages 644-645, Sections 2.1.1-2.1.5, contain very substantial text taken from the referenced articles that should be enclosed within quotation marks.

The online version of the original article can be found under doi:10.1007/s11207-008-9216-6.

V.V. Zharkova $(\bowtie)$

Department of Computing and Mathematics, University of Bradford, Bradford, UK

e-mail: v.v.zharkova@brad.ac.uk 


\section{Please note the following changes in the reference list:}

On page 622,

Allred, J.C., Hawley, S.L., Abbet, W.P., Carlosn, M.: 2005, Astrophys. J. 630, 573

should be replaced by

Allred, J.C., Hawley, S.L., Abbet, W.P., Carlsson, M.: 2005, Astrophys. J. 630, 573.

On page 662,

Besliu-Ionescu, D., Donea, A.C., Cally, P.S., Lindsey C.: 2006, In: Bothmer, V., Hady, A. (eds.) Solar Activity and Its Magnetic Origin, IAU Symp. 233, Cambridge University Press, Cambridge, 385

should be replaced by

Besliu-Ionescu, D., Donea, A.C., Cally, P.S., Lindsey C.: 2005, In: Danesy, D., Poedts, S., De Groof, A., Andries, J. (eds.) Proc. 11th European Solar Physics Meeting - The Dynamic Sun: Challenges for Theory and Observation, SP-596, ESA, Noordwijk, CDROM-111.1.

On page 663 ,

Hudson H.S., Fisher, G.H., Welsch, P.: 2008, Astrophys. J., in press

should be replaced by

Hudson H.S., Fisher, G.H., Welsch, B.T.: 2008, In: Howe, R., Komm, R.W., Balasubramaniam, K.S., Petrie, G.J.D. (eds.) Subsurface and Atmospheric Influences on Solar Activity, CS-383, Astron. Soc. Pac., San Francisco, 221.

On page 663,

Martínez-Oliveros, J.C., Moradi, H., Donea, A.-C.: 2008, Solar Phys. 251, 613

should be added.

On page 663,

Moradi, H., Donea, A.C., Besliu-Ionescu, D., Lindsey C., Cally, P.S.: 2006, Mon. Not. Roy. Astron. Soc. 373, 1155

should be changed to

Moradi, H., Donea, A.C., Lindsey, C., Besliu-Ionescu, D., Cally, P.S.: 2007, Mon. Not. Roy. Astron. Soc. 374, 1155.

The journal regrets these errors. 